\title{
A PECUÁRIA NO BIOMA PAMPA E A RESERVA LEGAL
}

\section{LIVESTOCK IN PAMPA BIOME AND LEGAL RESERVATION}

\begin{abstract}
SaUl de Oliveira Sichonany Neto
Bacharel em Direito pelo Centro Univeritário Franciscano - UNIFRA (2010); Especialista em Direito Tributário pela Universidade de Caxias do Sul - UCS (2012)

JERÔNIMO SIQUEIRA TYBUSCH Doutor em Ciências Humanas pela Universidade Federal de Santa Catarina - UFSC (2011); mestre em Direito Público pela Universidade do Vale do Rio dos Sinos - UNISINOS (2007); graduado em Direito pela Universidade de Santa Cruz do Sul - UNISC (2004). Professor Adjunto I da Universidade Federal de Santa Maria - UFSM. Professor Pesquisador I $U A B$. Coordenador do Projeto Justiça Ambiental em Redes Colaborativas: e-democracy e Ecologia Política na Sociedade Informacional Latino-Americana, contemplado com Auxílio Financeiro Edital Universal CNPq - 2011
\end{abstract}

\section{RESUMO}

O Código Florestal trouxe consigo a Reserva Legal, que visa proteger a vegetação nativa. Caracteriza-se pela reserva de um percentual da área dos imóveis rurais, na qual a vegetação nativa não pode ser suprimida. Em última análise, esse instrumento serve para preservar os biomas encontrados no Brasil. Nosso país possui seis biomas diferentes, dentre eles o Pampa, bioma localizado no Rio Grande do Sul. Em razão das características do Bioma Pampa, desenvolveu-se a pecuária. Ocorre que ainda não existem pesquisas suficientes acerca das atividades rurais que podem ser desenvolvidas nas áreas reservadas. Através da presente pesquisa chegou-se à conclusão de que o instituto da Reserva Legal limita o uso indiscriminado da propriedade privada rural, na medida em que obriga o produtor a preservar a vegetação nativa, não apresentando a lei qualquer empecilho para a exploração da pecuária baseada nas pastagens nativas, uma vez que não há a supressão da vegetação natural.

Palavras-chave: Bioma Pampa; Pecuária; Reserva Legal.

\begin{abstract}
The Forest Code has brought the legal reserve, which aims to protect native vegetation. It is characterized by reserving a percentage of the area of rural properties in which native vegetation cannot be suppressed. Lately this tool serves to preserve the biomes found in Brazil. Our country has six different biomes, including the Pampa biome located in Rio Grande do Sul. Because of Pampa biome's characteristics, livestock was developed. It happens that there are still no sufficient researches on rural activities that can be developed in reserved areas. Through this research it is possible to conclude that the Office of Legal Reserve limits the indiscriminate use of rural private property, insofar as it obliges the producer to preserve native vegetation, and then the law does not contain any hindrance to the exploitation of livestock based in native pastures, since there is no suppression of natural vegetation.
\end{abstract}

Keywords: Pampa Biome; Livestock; Legal Reserve.

\section{SUMÁRIO}

INTRODUÇAO; 1 RESERVA LEGAL: LIMITAÇÃO AO USO INDISCRIMINADO DA PROPRIEDADE RURAL; 2 BIOMAS BRASILEIROS: O BIOMA PAMPA E SUAS CARACTERÍSTICAS; 3 A PECUÁRIA NO BIOMA PAMPA: FORMA DE USO DEVIDO NA RESERVA LEGAL?; CONCLUSÃO; REFERÊNCIAS.

REDESG / Revista Direitos Emergentes na Sociedade Global - www.ufsm.br/redesg v. 1, n. 2, jul.dez/2012

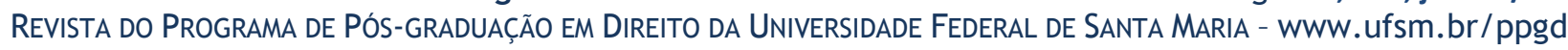




\section{INTRODUÇÃO}

O Código Florestal, desde sua primeira edição, apresentou uma forma de restrição ao uso indiscriminado do imóvel rural, instituto este que foi denominado de Reserva Legal pelo Código Florestal de 1965, nomenclatura mantida pela lei atual. A Reserva Legal, como o próprio nome diz, é a reserva de uma parte do imóvel rural para a preservação da vegetação nativa daquela região. Em última análise, este instrumento serve para preservar os biomas encontrados no Brasil. Nosso país, nesta senda, possui seis biomas diferentes, que variam de campos a florestas, com uma grande biodiversidade, e a legislação brasileira busca justamente a preservação desses biomas.

Entre os biomas nacionais encontra-se o Pampa, bioma localizado no Rio Grande do Sul, diferente de todos os outros, apresentando uma vegetação de gramíneas, com poucas árvores. Em razão das características do Bioma Pampa, as atividades rurais foram nele desenvolvidas, tais como a agricultura, a pecuária e a silvicultura. Dentre essas atividades produtivas existem algumas que degradam o meio ambiente e outras que ajudam a preservá-lo, podendo estas últimas desenvolverem-se em consonância com a Reserva Legal. Ocorre que ainda não existem pesquisas suficientes acerca das atividades rurais em relação a instrumentos protetivos encontrados nas leis nacionais, pairando dúvidas tanto para os pecuaristas quanto para a fiscalização pública.

Importante assinalar que o presente trabalho não tem a intenção de esgotar o tema e os assuntos abordados. Muito pelo contrário. A pretensão é que se levantem pontos de discussão e reflexão acerca do tema, para que tanto os órgãos de fiscalização ambiental quanto os proprietários ou possuidores rurais busquem esclarecimentos sobre a instituição da Reserva Legal.

A metodologia e estratégia de ação para viabilizar este artigo obedece ao trinômio: Teoria de Base; Procedimento e Técnica, os quais interpenetram-se em uma relação sistêmicocomplexa para configuração de um método que permita uma abordagem de pesquisa interdisciplinar, exigida pela escolha da temática, e em sinergia com as diferentes áreas do conhecimento: Ciências Rurais, Sociais Aplicadas e Ciências Humanas. 
Teoria de Base: 0 presente trabalho tem como referencial teórico a matriz epistemológica pragmático-sistêmica ${ }^{1,}$ que permite um enfoque sistêmico-complexo e interdisciplinar aos pesquisadores acerca do tema proposto. Foram utilizados autores que possibilitam uma visão interdisciplinar no direito, interligando saberes que compõem a Ciência Jurídica. Da mesma forma, alguns autores escolhidos são oriundos de outras áreas do saber, permitindo diálogos multidisciplinares no contexto da pesquisa.

Procedimento: Coletaram-se conteúdos, informações e dados para a análise e contextualização de diagnóstico em torno dos objetivos específicos, delimitando as etapas a serem cumpridas até o resultado final. Constituiu-se no desenvolvimento de seus resultados parciais em capítulos articulados e conexos, utilizando-se para isso de um referencial de dados bibliográficos e de mídia, caracterizando-se em fontes primárias e secundárias, tais como livros, revistas e periódicos especializados, meios de informação e dados, de origem em instituições públicas ou privadas, impressos, digitalizados ou virtualizados, nacionais e internacionais.

Técnica: Produção de resenhas, resumos, fichamentos, notas de síntese, bem como convergências e análises de dados, foram empreendidos ao longo das etapas de atividade de pesquisa projetadas ${ }^{2}$.

0 artigo está dividido em três capítulos. No primeiro capítulo será realizada uma análise do instituto da Reserva Legal, criado pelo Código Florestal de 1934, mantido pelo Código de 1965 e pela lei atual, editada em 2012, observando-se o objetivo de sua inserção na legislação pátria para a defesa do meio ambiente, a forma como é instituído, ou seja, será feita uma abordagem geral acerca do instituto.

Na segunda parte do trabalho, verificar-se-á o conceito de bioma e os biomas existentes no Brasil, com uma observação das características de cada um. Em seguida, será feita uma análise mais aprofundada sobre o Bioma Pampa, encontrado no Rio Grande do Sul, vislumbrandose suas características naturais, sua biodiversidade, formas de degradação e formas de preservação deste bioma. Ao final e ao cabo será analisada a pecuária desenvolvida no pampa,

\footnotetext{
${ }^{1}$ ROCHA, Leonel Severo. Epistemologia Jurídica e Democracia. São Leopoldo: UNISINOS, 1998, p.90 e segs. Trata da nova matriz epistemológica no Direito, denominada de pragmático-sistêmica, a qual permite aos estudiosos da ciências sociais aplicadas uma percepção diferenciada e transdisciplinar das áreas correlatas do conhecimento, que complementam o saber para as práticas jurídicas contemporâneas, diante dos novos desafios de regulação social na sociedade de risco.

${ }^{2}$ Embora tenham sido descritos separadamente os elementos componentes da metodologia, entende-se que os três aspectos "teoria de base, procedimento e técnica" são indivisíveis e comunicam-se constantemente na integralidade do projeto.

REDESG / Revista Direitos Emergentes na Sociedade Global - www.ufsm.br/redesg v. 1, n. 2, jul.dez/2012 Revista do Programa de Pós-graduaçÃo em DiREITO dA Universidade FEderal de SANTA MARIA - www.ufsm.br/ppgd
} 
para que se verifique se esta está em consonância, ou melhor, pode estar em consonância com a preservação do bioma e com o instituto da Reserva Legal.

\section{RESERVA LEGAL: LIMITAÇÃO AO USO INDISCRIMINADO DA PROPRIEDADE RURAL}

Dentre os diversos instrumentos de proteção ao meio ambiente existentes na legislação brasileira, um deles interfere diretamente nas propriedades rurais, qual seja: a Reserva Legal. Diante do cenário de agressões ao meio ambiente, como, por exemplo, a degradação do solo e da vegetação pela agricultura e outras práticas desenvolvidas no meio rural, as autoridades governamentais do mundo inteiro passaram a criar normas e padrões a serem seguidos na conservação do meio ambiente. Tanto é assim que o próprio direito à propriedade, previsto como direito fundamental pela Constituição Federal de 1988, sofre interferências e limitações para a proteção do meio ambiente e preservação dos biomas e vegetações nativas. Uma dessas interferências é a reserva de uma parte das propriedades rurais para a manutenção da vegetação nativa.

Independentemente de ter a proteção ao meio ambiente adquirido status constitucional apenas em 1988, a restrição ao direito de propriedade é relativamente antiga, sendo introduzida no ano de 1934. Conforme muito bem destaca Ozório Vieira Dutra, uma das inovações trazidas pelo Código Florestal de 1934 foi a limitação do poder de propriedade, a chamada "quarta parte", caracterizada pela reserva obrigatória de vinte e cinco por cento de vegetação nativa de cada propriedade rural, ou seja, de acordo com o antigo Código Florestal, o proprietário de terras situadas na zona rural deveria preservar a vegetação nativa em, no mínimo, vinte e cinco por cento da extensão da propriedade. Afirma o autor que tal limitação foi motivo de indignação por parte de fazendeiros e madeireiros, os quais consideraram tal medida como um sacrifício ao direito de propriedade e uma grave restrição ao uso econômico do imóvel rural. ${ }^{3}$ Desta forma, de acordo com Sirvinkas, o instituto que com o Código Florestal de 1965 foi intitulado de Reserva Legal é "a preservação de parte de uma área maior de determinada propriedade particular com o objetivo de preservação da vegetação ali existente." ${ }^{4}$ Assim, seguindo o Decreto 23.793/345, o

\footnotetext{
${ }^{3}$ DUTRA, Ozório Vieira. Reserva legal: direito ambiental. São Borja: Conceito, 2009. p. 15-16.

${ }^{4}$ SIRVINSKAS, Luís Paulo. Manual de direito ambiental. São Paulo: Saraiva, 2009. p. 452.

REDESG / Revista Direitos Emergentes na Sociedade Global - www.ufsm.br/redesg v. 1, n. 2, jul.dez/2012 Revista do Programa de Pós-graduaçÃo em DiREITO dA Universidade FEderal de SANTA MARIA - www.ufsm.br/ppgd
} 
Código Florestal, Lei $4.771 / 65^{6}$, manteve as limitações às propriedades rurais, atribuindo, conforme visto supra, o nome de Reserva Legal. O conceito deste instituto é encontrado no atual Código Florestal, Lei 12.651/2012, que não alterou substancialmente o conceito trazido pela lei anterior.

Diz o inciso III, do parágrafo $3^{\circ}$, do artigo $1^{\circ}$ que Reserva Legal é a:

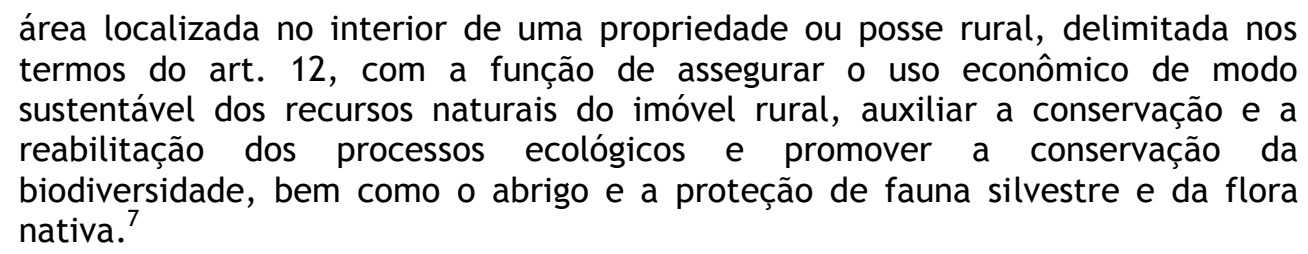

Porém, diferentemente do Código Florestal 1934, que determinava a reserva de um quarto da propriedade rural para preservação da vegetação nativa, o atual Código Florestal, em seu artigo 12, traz quatro modalidades de reservas legais. Então, a reserva legal na Amazônia Legal será de oitenta por cento da propriedade rural, se esta for localizada em área de florestas; trinta e cinco por cento da propriedade localizada no cerrado; vinte por cento em áreas de campos; bem como vinte por cento nas demais regiões do país; atentando-se sempre o plano da bacia hidrográfica, o Zoneamento Ecológico-Econômico, a formação de corredores ecológicos com outra Reserva Legal, com Área de Preservação Permanente, com Unidade de Conservação ou com outra área legalmente protegida, as áreas de maior importância para a conservação da biodiversidade e as áreas de maior fragilidade ambiental (artigo 14, incisos I a $V$ da Lei 12.651/12), devendo ser submetida à aprovação do órgão estadual integrante do Sisnama ou instituição por ele habilitada. O imóvel, para ter aprovada a Reserva Legal, deve ser incluído no Cadastro Ambiental Rural - CAR - cadastro este previsto no artigo 29 da nova lei.

Portanto, existem percentuais diferentes para diferentes regiões do país, de acordo com a vegetação ali existente. Desta forma, o que pretendeu o legislador foi a reserva de áreas

\footnotetext{
${ }^{5}$ BRASIL. Decreto $n^{\circ} 23.793,23$ de janeiro de 1934. Aprova o Código Florestal que com este baixa. Diário Oficial da República Federativa do Brasil, Brasília, DF, 21 mar. 1935. Disponível em: < http://www.planalto.gov.br/ccivil_03/decreto/1930-1949/d23793.htm> Acesso em: 28 nov. 2012.

${ }^{6}$ BRASIL. Lei 4.771, 15 de setembro de 1965. Institui o novo Código Florestal. Diário Oficial da República Federativa do Brasil, Brasília, DF, 16 set. 1965. Disponível em <http://www.planalto.gov.br/ccivil_03/Leis/L4771.htm> Acesso em: 28 mai. 2010.

${ }^{7}$ BRASIL. Lei $n^{\circ}$ 12.651, 25 de maio de 2012. Dispõe sobre a proteção da vegetação nativa. Diário Oficial da República Federativa do Brasil, Brasília, DF, 28 mai. 2012. Disponível em < http://www.planalto.gov.br/ccivil_03/_Ato2011-2014/2012/Lei/L12651.htm> Acesso em: 27 nov. 2012.

REDESG / Revista Direitos Emergentes na Sociedade Global - www.ufsm.br/redesg v. 1, n. 2, jul.dez/2012 Revista do Programa de Pós-graduaçÃo em DiREITO dA Universidade FEderal de SANTA MARIA - www.ufsm.br/ppgd
} 
maiores para a preservação da vegetação nativa que mais sofre ameaça, onde pode-se apontar como prova disso a extensa área que deve ser reservada na Amazônia Legal, uma das florestas mais importantes do mundo, que vem sofrendo com o desmatamento. Assim, o objetivo principal é a proteção da vegetação típica de cada região, variando a área destinada para a Reserva Legal de acordo com a importância de tal vegetação, bem como com a possibilidade de sua extinção.

De outra banda, verifica-se que a vegetação da reserva legal não pode ser suprimida, tendo o proprietário ou o possuidor a possibilidade de utilizar a área apenas sob o regime de manejo sustentável, desde que previamente aprovado pelo órgão competente do Sisnama (artigo 17, $\S 1^{\circ}$ da Lei 12.651/12). Assim, importante salientar que não se perde a posse ou a propriedade em razão da Reserva Legal, muito menos se proíbe o uso da área. 0 que se pretende é que haja a preservação da vegetação nativa, podendo haver a utilização da área de forma compatível com a proteção almejada. Conforme lição de Granziera, ao tratar do Código Florestal anterior, mas aplicável à atual lei, "O que se proíbe é a supressão da cobertura vegetal, sem o que não se cumpre a função ambiental da Reserva Legal"8. No mesmo sentido a autora diz que a “área destinada à Reserva Legal não fica alijada da propriedade, na medida em que é possível implantar usos compatíveis com a proteção" ". Neste mesmo ínterim, Granziera destaca que a Reserva Legal, que tem por finalidade a proteção do meio ambiente, impõe certas restrições ao uso da propriedade, sem que isso gere qualquer tipo de indenização, mesmo porque a função social da propriedade rural abarca a idéia de preservação ambiental e uso racional dos recursos naturais. ${ }^{10}$ Ainda, a Reserva Legal pode ser instituída em condomínio entre mais de uma propriedade, sendo medida em cada imóvel pertencente ou não ao mesmo proprietário, devendo, obrigatoriamente, respeitar os percentuais mínimos em cada propriedade, que devem ser aprovados pelo órgão ambiental competente, conforme artigo 16 do atual Código.

De acordo com Sirvinkas, que destaca a lei anterior, que não foi alterada substancialmente neste ponto:

A reserva legal será medida em cada propriedade pertencente ou não ao mesmo proprietário, podendo ser instituída em regime de condomínio entre mais de uma propriedade, respeitando o percentual legal em relação a cada imóvel, mediante a aprovação do órgão ambiental estadual competente e as devidas averbações referentes a todos os imóveis envolvidos (art. 16, §§ $4^{\circ}$ e 11, da Lei $n$.

\footnotetext{
${ }^{8}$ GRANZIERA, Maria Luiza Machado. Direito ambiental. São Paulo: Atlas, 2009. p. 356.

${ }^{9}$ Idem, ibidem.

${ }^{10}$ Idem, ibidem.
}

REDESG / Revista Direitos Emergentes na Sociedade Global - www.ufsm.br/redesg v. 1, n. 2, jul.dez/2012 Revista do Programa de Pós-graduaÇão em DiReITo da UnIVERSIDAde Federal de SANTA MARIA - www.ufsm.br/ppgd 


\section{$4.771 / 65) .{ }^{11}$}

Cabe frisar, outrossim, que a escolha da área que será destinada à Reserva Legal é feita pelo próprio proprietário ou posseiro, que deverá submeter à análise do órgão ambiental competente, devendo tal escolha observar a função social da propriedade, bem como deve indicar a área mais relevante para o meio ambiente, devendo seguir os critérios e estudos delimitados no artigo 14, já citados anteriormente.

Granziera afirma que:

A localização e delimitação da área destinada à Reserva Legal é proposta pelo proprietário ou posseiro, e deve ser aprovada pelo órgão ambiental estadual competente, que considerará, em primeiro lugar, em sua decisão, a função social, que se cumpre quando a propriedade rural atende, simultaneamente, segundo critérios e graus de exigência estabelecidos em lei, aos requisitos previstos no art. $186 \mathrm{da} \mathrm{CF} / 88 .^{12}$

Uma outra determinação da lei, constante no artigo 18 do novo Código Florestal, é que a Reserva Legal depois de ser instituída não pode sofrer qualquer modificação, mesmo que haja a transmissão da propriedade a qualquer título. Em razão da impossibilidade de alteração da destinação da área de Reserva Legal, refere Edis Milaré que a reserva é uma obrigação que recai sobre o proprietário do imóvel, independentemente da pessoa ou da forma de aquisição da propriedade, estando ligada à própria coisa, equiparando-se a “Reserva Florestal Legal a uma obrigação propter rem, ônus real que recai sobre o imóvel e que obriga, em qualquer circunstância, ao seu proprietário e a todos que o sucedem em tal condição"13.

Diante de todo o exposto acima, verifica-se que a Reserva Legal é um instituto do direito ambiental brasileiro que visa a preservação da vegetação nativa de determinadas regiões, incidindo sobre propriedade ou posse rurais, possuindo, de acordo com a região e o tipo de vegetação encontrada, diferentes percentuais a serem seguidos. Ainda, vislumbra-se que uma vez constituída a Reserva Legal, sua finalidade não pode ser alterada nem a vegetação suprimida. Portanto, a lei buscou formas de preservar a natureza, através da preservação da vegetação nativa, em razão dos abusos vistos, como queimadas, uso indevido do solo, dentre outros.

\footnotetext{
${ }^{11}$ SIRVINSKAS, Luís Paulo. Manual de direito ambiental. São Paulo: Saraiva, 2009. p. 454.

12 GRANZIERA, Maria Luiza Machado. Direito ambiental. São Paulo: Atlas, 2009. p. 357.

13 MILARÉ, Edis. Direito do ambiente: doutrina, jurisprudência, glossário. São Paulo: Revista dos Tribunais, 2007. p. 703.

REDESG / Revista Direitos Emergentes na Sociedade Global - www.ufsm.br/redesg v. 1, n. 2, jul.dez/2012 Revista do Programa de Pós-graduaÇão em DiReITo da UnIVERSIDAde Federal de SANTA MARIA - www.ufsm.br/ppgd
} 


\title{
2 BIOMAS BRASILEIROS: O BIOMA PAMPA E SUAS CARACTERÍSTICAS
}

A Reserva Legal, conforme visto alhures, tem por objetivo a preservação da vegetação nativa das diversas regiões do país, ou seja, com a imposição da reserva nas propriedades rurais o que se pretende preservar é um dos elementos dos biomas, qual seja, a flora. Neste sentido, a flora é apenas um dos elementos integrantes de um bioma, que é composto por diversos outros elementos, tais como a fauna e o solo. Importante, então, apresentar o conceito de bioma para as ciências biológicas. Desta forma, segundo o ecologista Leopoldo Magno Coutinho, Bioma é:

\begin{abstract}
uma área do espaço geográfico, com dimensões de até mais de um milhão de quilômetros quadrados, que tem por características a uniformidade de um macroclima definido, de uma determinada fitofisionomia ou formação vegetal, de uma fauna e outros organismos vivos associados, e de outras condições ambientais, como a altitude, o solo, alagamentos, o fogo, a salinidade, entre outros. Estas características todas lhe conferem uma estrutura e uma funcionalidade peculiares, uma ecologia própria. ${ }^{14}$
\end{abstract}

No mesmo sentido encontra-se o conceito apresentado por Eridiane Lopes da Silva, que utilizando como fonte o IBGE diz que:

Bioma é um conjunto de vida (vegetal e animal) constituído pelo agrupamento de tipos de vegetação próximos e identificáveis em escala regional, com condições de solo e clima similares e história compartilhada de mudanças, o que resulta em uma diversidade biológica própria daquela região. ${ }^{15}$

Portanto, ao se analisar os dois conceitos, pode-se entender que bioma é uma área do espaço geográfico que tem condições de clima definidos e similares, com cobertura vegetal e uma fauna similares, e com outras características definidas, tais como solo, altitude, relevo, alagamentos, entre outros, resultando, assim, em uma diversidade biológica específica de determinada região.

\footnotetext{
${ }^{14}$ COUTINHO, Leopoldo Magno. O conceito de bioma. Acta Bot. Bras., São Paulo, v. 20, n. 1, mar. 2006 Disponível em <http://www.scielo.br/scielo.php?script=sci_arttext\&pid=S0102$33062006000100002 \&$ tng=pt\&nrm=iso>. Acesso em 27 de maio de 2010.

${ }^{15}$ SEMINÁRIO SULAMERICANO DO BIOMA PAMPA, 1., 2006, Alegrete. Bioma Pampa. Alegrete: IBAMA, 2006. s.p.

REDESG / Revista Direitos Emergentes na Sociedade Global - www.ufsm.br/redesg v. 1, n. 2, jul.dez/2012

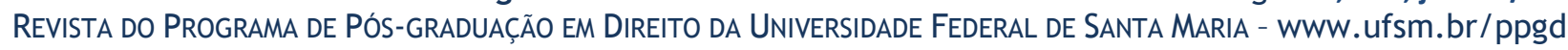


No Brasil, existem seis diferentes biomas, de acordo com informações do Instituto Brasileiro de Geografia e Estatística (IBGE), quais sejam: Bioma Amazônia, Bioma Mata Atlântica, Bioma Caatinga, Bioma Cerrado, Bioma Pantanal e Bioma Pampa. De acordo com este instituto, a nomenclatura adotada aos Biomas brasileiros tem como base a vegetação predominante ou o relevo. $^{16}$

O Bioma Amazônia ocupa uma área de aproximadamente $4.196 .943 \mathrm{~km}^{2}$, correspondendo a 49,29\% da área total do Brasil. O Bioma Mata Atlântica, por sua vez, ocupa cerca de $1.110 .182 \mathrm{~km}^{2}$ de área, perfazendo 33,04\% do território brasileiro. Já o Bioma Caatinga ocupa uma área aproximada de $844.453 \mathrm{~km}^{2}$ do Brasil, o que corresponde a 9,92\% da área total do país. O Bioma Cerrado tem área aproximada de $2.036 .448 \mathrm{~km}^{2}$, ocupando $23,92 \%$ do território nacional. Ainda, o Bioma Pantanal ocupa cerca de $150.355 \mathrm{~km}^{2}$, o que condiz a 1,76\% da país. Por fim, o Bioma Pampa ocupa cerca de $176.496 \mathrm{~km}^{2}$, correspondendo a 2,07\% do território pátrio.

Pelo fato de ser o Bioma Pampa o objeto do presente trabalho, este será melhor analisado. Conforme explica Eridiane Lopes da Silva, “de maneira genérica, os campos da região Sul do Brasil são denominados como "pampa", termo de origem indígena para "região plana"”, 17. Portanto, o nome atribuído ao bioma em apreço possui origem na língua dos nativos que povoavam a região sul, que denominavam a região onde habitavam como pampa, ou seja, região plana. A autora refere ainda que a denominação "pampa" corresponde somente a um dos tipos de campo, mais encontrado ao sul do Rio Grande do Sul, atingindo ainda regiões da Argentina e do Uruguai ${ }^{18}$.

O Bioma Pampa, também chamado por alguns autores como Bioma Campos Sulinos ${ }^{19}$, foi reconhecido como tal apenas em 2004, sendo um desmembramento do Bioma Mata Atlântica. Assim, antes de 2004, o bioma estudado fazia parte do Bioma Mata Atlântica. Em razão de ter o IBGE atribuído a nomenclatura Bioma Pampa ao reconhecê-lo, será este nome o utilizado no presente artigo.

16 BRASIL. Instituto Brasileiro de Geografia e Estatística (IBGE). Disponível em: <http://www.ibge.gov.br/home/presidencia/noticias/noticia_visualiza.php?id_noticia=169> Acesso em: 29 mai. 2010.

${ }^{17}$ SEMINÁRIO SULAMERICANO DO BIOMA PAMPA, 1., 2006, Alegrete. Bioma Pampa. Alegrete: IBAMA, 2006. S.p.

${ }_{18}$ Idem.

${ }^{19}$ CARVALHO, P.C.F. et al. Produção Animal no Bioma Campos Sulinos. Brazilian Journal of Animal Science, João Pessoa, v. 35, n. Supl. Esp., p. 156-202, 2006. s. p. 
Conforme visto acima, o Rio Grande do Sul é o único estado brasileiro em que se pode encontrar o Pampa, que é definido por um conjunto de vegetação de campo em relevo de planície. ${ }^{20}$ De acordo com Malvezzi, o "Pampa Gaúcho é bastante diferente dos demais biomas brasileiros. Dominado por gramíneas, com poucas árvores, sempre foi considerado mais apropriado para a criação do gado.” Refere o autor também que o Bioma Pampa não é o único encontrado no Rio Grande do Sul, ocupando $63 \%$ da área deste estado. ${ }^{21}$ Assim, são encontrados dois Biomas no Rio Grande do Sul, quais sejam: o Bioma Pampa, reconhecido como tal apenas em 2004, e o Bioma Mata Atlântica, do qual se desmembrou o bioma anterior.

De acordo com Edis Milaré, o pampa é composto por:

(...) terras baixas e predominantemente planas, com suas colinas arredondadas, as "coxilhas", cobertas de plantas herbáceas. O clima é temperado e subúmido. 0 ecossistema, em seu conjunto, é menos diversificado. Pelas características que apresentavam ao colonizador, as pradarias do sul acolheram a cultura de grãos e a pecuária. ${ }^{22}$

Segundo Carvalho, o Pampa "é reconhecido como sendo um Bioma que contém uma rica biodiversidade. Ele é o habitat de 3.000 plantas vasculares, 385 espécies de pássaros e 90 mamíferos terrestres" 23 .

No mesmo sentido, destaca Ilsi lob Boldrini que:

Os campos deste bioma, pela sua diversidade biológica (flora, invertebrados, peixes, répteis e anfíbios, aves e mamíferos), além dos fatores abióticos e pressão antrópica a que estão submetidos, estão contemplados como área de extrema importância biológica para conservação, as regiões da Campanha Gaúcha, Serra do Sudeste e Planície Costeira e com muito alta importância biológica para conservação, os Campos do Planalto e os Campos de Baixada de Bagé. ${ }^{24}$

${ }^{20}$ SEMINÁRIO SULAMERICANO DO BIOMA PAMPA, 1., 2006, Alegrete. Bioma Pampa. Alegrete: IBAMA, 2006. ${ }_{21}$. p.

MALVEZZI, Roberto.

Os biomas brasileiros.

Disponível em: <http://www.coepbrasil.org.br/portal/Publico/apresentarArquivo.aspx?ID=2097 > Acesso em: 31 mai. 2010.

${ }_{22}$ MILARÉ, Edis. Direito do ambiente: doutrina, jurisprudência, glossário. São Paulo: Revista dos Tribunais, 2007. p. 632.

${ }^{23}$ CARVALHO, P.C.F. et al. Produção Animal no Bioma Campos Sulinos. Brazilian Journal of Animal Science, João Pessoa, v. 35, n. Supl. Esp., p. 156-202, 2006. s. p.

${ }_{24}$ SIMPÓSIO DE FORRAGEIRAS E PRODUÇÃO ANIMAL, 1.,2006, Porto Alegre. Anais. Biodiversidade dos Campos Sulinos. Porto Alegre: ULBRA, 2006. p. 17.

REDESG / Revista Direitos Emergentes na Sociedade Global - www.ufsm.br/redesg v. 1, n. 2, jul.dez/2012 Revista do Programa de Pós-graduaÇão em DiReITo da UnIVERSIDAde Federal de SANTA MARIA - www.ufsm.br/ppgd 
Ocorre que mesmo sendo um bioma que apresenta grande riqueza de vida vegetal e animal a preocupação com a sua preservação ainda não é a mesma em relação a outros biomas brasileiros. Neste sentido, destaca Carvalho que o pampa, “dentre os Biomas brasileiros, tem recebido menos atenção em comparação aos demais (e.g., Bioma Amazônia, que é motivo de preocupação mundial)"25. E continua o autor dizendo que em consequiência da ausência da devida atenção ao Bioma Pampa é que as ameaças à sua biodiversidade, bem como o nível de tais ameaças não estão suficientemente reconhecidos ${ }^{26}$.

Boldrini destaca algumas das ameaças e alterações que o Pampa vem sofrendo, que merecem ser apresentadas. Aponta a autora a substituição do campo por agricultura mecanizada, com a utilização de altas doses de fungicidas e pesticidas, que acabam por desgastar o solo; a perda de habitats e de variabilidade genética; a utilização de queimadas para permitir o rebrote da vegetação a ser utilizada como alimento para o gado, que causa a seleção de espécies resistentes ao fogo e a eliminação das que são suscetíveis; o florestamento de áreas de campo com Pinus, Eucaliptos e Acácias, visando atender a indústria madeireira e de celulose, o que ocasiona em uma mudança drástica do cenário da região; e a introdução de espécies exóticas na região, que acaba por sobrepor-se à vegetação nativa. ${ }^{27}$ Eridiane Lopes da Silva acrescenta a estas ameaças a exploração excessiva de espécies de plantas e animais; o uso de híbridos e monoculturas na agroindústria e nos programas de reflorestamento; e as mudanças climáticas, que podem acarretar na alteração da biodiversidade. ${ }^{28}$

Neste ínterim, verifica-se que são várias as formas de ameaça à biodiversidade do Bioma Pampa, as quais acarretam, portanto, uma diminuição nas áreas de vegetação nativa, que são substituídas, como visto acima, por espécies alienígenas exóticas, ou por florestas em lugares de predominância de campos, em razão da necessidade das indústrias madeireiras e de celulose, além das queimadas, da agricultura degradante, dentre outros.

Diante desse cenário de ameaça é necessário que medidas sejam tomadas para frear a perda da biodiversidade. Neste diapasão, Boldrini apresenta algumas medidas que merecem destaque. Refere a autora que as áreas de Unidades de Conservação dos campos naturais devem

${ }^{25}$ CARVALHO, P.C.F. et al. Produção Animal no Bioma Campos Sulinos. Brazilian Journal of Animal Science, João Pessoa, v. 35, n. Supl. Esp., p. 156-202, 2006. s. p.

${ }^{26}$ Idem.

27 SIMPÓSIO DE FORRAGEIRAS E PRODUÇÃO ANIMAL, 1.,2006, Porto Alegre. Anais. Biodiversidade dos Campos Sulinos. Porto Alegre: ULBRA, 2006. p. 20-21.

${ }^{28}$ SEMINÁRIO SULAMERICANO DO BIOMA PAMPA, 1., 2006, Alegrete. Bioma Pampa. Alegrete: IBAMA, 2006. S.p.

REDESG / Revista Direitos Emergentes na Sociedade Global - www.ufsm.br/redesg v. 1, n. 2, jul.dez/2012 Revista do Programa de Pós-graduação em DiReIto da Universidade Federal de SANTA MARIa - www.ufsm.br/ppgd 
aumentar, uma vez que apenas $0,36 \%$ da área de domínio campestre é contemplada; ordenamento do plantio de culturas como a silvicultura de Pinus, Eucaliptos, árvores frutíferas, de grãos, de acordo com cada região, levando-se em consideração a vegetação característica dominante, a fauna, o solo, o relevo e o clima; controle de mudas de Pinus "escapadas de cultivo" mediante a limpeza e avaliação periódicas das áreas de entorno do plantio, considerando que as sementes de Pinus podem dispersar-se até 30 quilômetros de distância da planta-mãe; manejo de campos para o desenvolvimento da pecuária, sem a utilização de fogo; aumento dos mecanismos de controle sobre as fontes de poluição geradas pelas monoculturas; fiscalização efetiva da manutenção das áreas de Reserva Legal instituídas; incentivo para o aproveitamento e conservação das belezas naturais da região, com vistas ao ecoturismo; incentivo à produção de produtos livres de agrotóxicos; e esclarecimento dos proprietários sobre os problemas trazidos pela caça, captura e comércio ilegal de espécies da fauna silvstre. ${ }^{29}$

Diante das diversas medidas apresentadas com o intuito de frear as ações que ameaçam a biodiversidade do Bioma Pampa, verifica-se que em sua grande maioria as atitudes devem ser tomadas pelos particulares, que precisam ter consciência ambiental. Por seu turno, o Estado pode tomar iniciativas de fiscalização e programas de conscientização para que o pampa não se descaracterize por completo.

Mesmo já apresentadas as ações que geram degradação do meio ambiente e ameaçam a biodiversidade do pampa, bem como as medidas que devem ser tomadas, mostra-se necessário que se cite Elissandra Gomes, que apresenta um fato importante, qual seja: a pecuária extensiva como forma de preservação do Bioma Pampa. Diz a autora que:

Não se conhece exatamente o que resta de vegetação original do Pampa e o grau de preservação destas áreas. As atividades agrícolas de larga escala como o arroz e o soja são os principais fatores de degradação do bioma. Grandes áreas alagadas, onde antes havia banhados, foram drenadas para o plantio de arroz. Não existem números oficiais sobre as áreas de banhados perdidas. A fruticultura também vem gerando impacto, mas em menor escala por ocupar áreas menores. A degradação também ocorre pelo pastoreio intensivo. Esta atividade é um dos principais fatores de aceleração do processo de arenização que ocorre em parte do Estado: são terras transformando-se em grandes areais, com enormes voçorocas, em um processo popularmente chamado de desertificação. Este é um processo natural intensificado pelo uso incorreto do solo. Por outro lado, foi a pecuária extensiva, praticada em todo o Pampa, que garantiu a sua preservação.

29 SIMPÓSIO DE FORRAGEIRAS E PRODUÇÃO ANIMAL, 1.,2006, Porto Alegre. Anais. Biodiversidade dos Campos Sulinos. Porto Alegre: ULBRA, 2006. p. 21-22.

REDESG / Revista Direitos Emergentes na Sociedade Global - www.ufsm.br/redesg v. 1, n. 2, jul.dez/2012 Revista do Programa de Pós-graduaçÃo em DiREITO dA Universidade FEderal de SANTA MARIA - www.ufsm.br/ppgd 
A criação de gado em vastos campos é a imagem da cultura gaúcha, a identidade do povo que se identifica como gaúcho ao invés de sul-rio-grandense. ${ }^{30}$

Portanto, a pecuária em momento algum foi citada como uma forma de ameaça à biodiversidade existente no Rio Grande do Sul. Pelo contrário, de acordo com a citação supra, que inclusive é uma das medidas sugeridas por Boldrini, ao se realizar o manejo de campos para o desenvolvimento da pecuária extensiva, ou seja, ao se preparar o campo nativo para a pecuária, estar-se-á tomando uma medida de preservação do bioma, e não de degradação.

\section{A PECUÁRIA NO BIOMA PAMPA: FORMA DE USO DEVIDO NA RESERVA}

\section{LEGAL?}

Conforme se observou acima, a atividade pecuária desenvolvida no Rio Grande do Sul não é um agente degradante, pelo contrário, é capaz de preservar o meio ambiente, ou seja, preservar o Bioma Pampa. Contudo, não basta apenas fazer tal alegação sem que se analise melhor a pecuária praticada no pampa gaúcho. Desta forma, far-se-á uma análise mais aprofundada sobre $o$ assunto.

A pecuária é desenvolvida no Rio Grande do Sul há aproximadamente quatro séculos. Essa atividade foi introduzida no Bioma Pampa em razão das características ambientais aqui encontradas, quais sejam: vegetação herbácea, dominada por gramíneas, com poucas árvores e relevo de planície, e essa vegetação mostrou-se resistente e adaptável aos impactos gerados pelo homem com a utilização de fogo e a criação de mamíferos domésticos.

O fato é que os primeiros colonizadores europeus encontraram um ambiente pastoril extremamente favorável aos herbívoros aqui introduzidos: vegetação herbácea resiliente aos impactos dos dois principais elementos de distúrbio manipulados pelo homem, o fogo e o pastejo de mamíferos domésticos. Estimase que a introdução de eqüinos e bovinos nos Campos Sulinos tenha ocorrido entre 1626 e 1628, com a instalação das Missões jesuíticas ao longo do Rio Uruguai. ${ }^{31}$

Como se pode observar, os primeiros europeus que colonizaram a região sul do Brasil

\footnotetext{
${ }^{30}$ GOMES, Elissandra et. al. 0 impacto da crise econômica americana no bioma pampa. Disponível em: <http://www.eumed.net/cursecon/ecolat/br/08/gpfrmp.htm> Acesso em: 02 jun. 2010.

${ }^{31}$ CARVALHO, P.C.F. et al. Produção Animal no Bioma Campos Sulinos. Brazilian Journal of Animal Science, João Pessoa, v. 35, n. Supl. Esp., p. 156-202, 2006. s. p.

REDESG / Revista Direitos Emergentes na Sociedade Global - www.ufsm.br/redesg v. 1, n. 2, jul.dez/2012

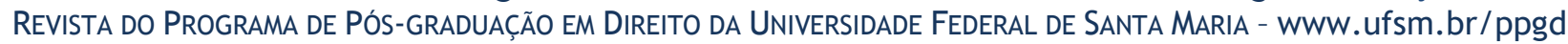


trouxeram consigo a pecuária, em razão das características aqui encontradas, configurando até hoje uma das principais atividades econômicas do estado. De acordo com o referido alhures, a vegetação nativa encontrada no Rio Grande do Sul, mais especificamente no Bioma Pampa, foi um dos fatores determinantes para a introdução da pecuária na região. Existem no estado mais de 400 espécies de gramíneas forrageiras nativas e aproximadamente 150 espécies de leguminosas, sendo o pampa detentor de uma rica fonte nutricional para o gado, facilitando o desenvolvimento da pecuária. De acordo com Carlos Guilherme Silveira Pedreira as forragens são as partes comestíveis das plantas, exceto os grãos, que podem servir na alimentação dos animais em pastejo, ou colhidas e fornecidas ${ }^{32}$, consequentemente, as gramíneas forrageiras são aquelas capazes de produzir as forragens. Já leguminosas, segundo o autor referido, são as únicas espécies de forrageiras que têm a capacidade de incorporar nitrogênio atmosférico ao sistema solo-planta, diminuindo o custo da pastagem, em razão de não necessitar somente da uréia para captação de nitrogênio ${ }^{33}$.

Aino V. A. Jacques e Carlos Nabinger referem que:

O Rio Grande do Sul possui mais de 400 espécies de gramíneas forrageiras nativas e cerca de 150 espécies de leguminosas, para ficarmos somente com estas duas famílias. Pesquisas realizadas nas universidades e centros de pesquisa mostram o indiscutível potencial das espécies forrageiras nativas, adaptadas às nossas condições há cerca de 200 mil anos como componentes do "bioma pastagens naturais". ${ }^{34}$

Em virtude do potencial natural do Bioma Pampa, a maior fonte de alimento de animais para a produção pecuária advém da vegetação nativa. Carvalho destaca que as "pastagens naturais componentes do Bioma Campos Sulinos representam a base da alimentação dos rebanhos de corte no Rio Grande do Sul”. ${ }^{35}$ Esta afirmação se dá com base em estatística apresentada pelo próprio autor, onde é demonstrada a distribuição média porcentual das áreas de pastagem em relação à área pastoril total do Rio Grande do Sul. Neste ínterim, afirma Carvalho que $69 \%$ é de cobertura de pastagem nativa, 20,2\% é de pastagem anual de inverno,

\footnotetext{
32 PEDREIRA, Carlos Guilherme Silveira. Avanços metodológicos na avaliação de pastagens. Piracicaba: USP.

${ }^{33}$ Idem.

34 SIMPÓSIO DE FORRAGEIRAS E PRODUÇÃO ANIMAL, 1.,2006, Porto Alegre. Anais. Biodiversidade dos Campos Sulinos. Porto Alegre: ULBRA, 2006. op. cit. p. 9.

${ }^{35}$ CARVALHO, P.C.F. et al. Produção Animal no Bioma Campos Sulinos. Brazilian Journal of Animal Science, João Pessoa, v. 35, n. Supl. Esp., p. 156-202, 2006. s. p.

REDESG / Revista Direitos Emergentes na Sociedade Global - www.ufsm.br/redesg v. 1, n. 2, jul.dez/2012 Revista do Programa de Pós-graduação em DiReITo da Universidade Federal de SANTA MARIA - www.ufsm.br/ppgd
} 
$5,4 \%$ é constituída por pastagem natural melhorada, $4 \%$ é de pastagem cultivada perene, e 1,4\% apresenta como cobertura vegetal pastagem anual de verão. ${ }^{36}$

Pastagem nativa é constituída pela vegetação natural, são as gramíneas nativas de determinada região. Por pastagem natural melhorada entende-se que são as pastagens naturais onde são feitas roçadas, introdução de outras espécies por plantio direto, correção do solo, etc. A pastagem anual de inverno é uma pastagem semeada, que produz no período do inverno e permanece somente no ano da semeadura. A pastagem anual de verão, por seu turno, é uma pastagem semeada, como a de inverno, porém produz apenas durante o verão, devendo ser semeada todos os anos, por permanecer apenas no ano de sua semeadura. Por fim, as pastagens perenes são espécies que possuem ressemeadura natural, ou seja, uma vez plantadas elas permanecem além do ano de sua semeadura, não precisando mais serem plantadas. Cumpre esclarecer que os conceitos supra são apresentados por Carvalho. ${ }^{37}$

Mesmo sendo a pastagem nativa a principal fonte de alimento para a pecuária, os campos nativos apresentam algumas variáveis que podem diminuir a produtividade ou fazer com que o produtor opte por outros tipos de pastagens, como as anuais de verão ou de inverno. Uma destas variáveis, e sem dúvida a que mais influencia na substituição da pastagem natural é que os campos naturais apresentam capacidade de suporte baixa, ou seja, quando se trata de vegetação nativa a carga animal por hectare é menor que em pastagens cultivadas. Outra variável é a alta variação de capacidade de suporte de região para região dentro do Bioma, pois depende do tipo de solo e das condições do clima que predominam na região.

Neste sentido, Carlos Nabinger afirma que o campo nativo:

(...) apresenta capacidade de suporte naturalmente muito mais baixa, uma vez que sua produtividade depende da fertilidade natural do solo. Além de apresentar uma capacidade de suporte mais baixa que as pastagens cultivadas adubadas, esta também é extremamente variável de região para região, em função do tipo de solo e das condições climáticas predominantes. No entanto, continua a representar a forma mais barata de produzir carne nesta região do país, desde que corretamente manejado. ${ }^{38}$

Porém, os campos nativos podem ter sua produtividade elevada com ou sem a intervenção de tecnologia, em diferentes níveis e com diferentes custos, de acordo com a

36 Idem.

${ }^{37}$ Idem.

38 SIMPÓSIO DE FORRAGEIRAS E PRODUÇÃO ANIMAL, 1.,2006, Porto Alegre. Anais. Biodiversidade dos Campos Sulinos. Porto Alegre: ULBRA, 2006. p. 29.

REDESG / Revista Direitos Emergentes na Sociedade Global - www.ufsm.br/redesg v. 1, n. 2, jul.dez/2012 Revista do Programa de Pós-graduação em Direito da Universidade Federal de Santa Maria - www.ufsm.br/ppgd 
tecnologia empregada. Dentre as medidas a serem adotadas que podem aumentar a produtividade pode-se citar: ajuste de carga animal, correção e fertilização do solo e cultivo de espécies forrageiras de inverno. O ajuste de carga animal significa, conforme explicação de Carlos Nabinger, "controlar o nível de forragem, ou seja, a quantidade de pasto que cada animal deve encontrar diariamente a sua disposição". ${ }^{39}$ Esta medida influencia na produtividade em virtude de que ao aumentar-se a disponibilidade de pasto diária para o animal, o desempenho individual aumenta, uma vez que comerá mais, podendo selecionar o que comer em termos de partes da planta e mesmo de espécies. ${ }^{40}$

No que tange a correção e fertilização do solo, esta será utilizada quando as condições de fertilidade do solo são baixas, onde o uso de fertilizantes torna-se essencial. ${ }^{41}$ Carvalho cita o calcário, o fósforo, o potássio e o nitrogênio como fertilizantes. ${ }^{42}$ Por fim, utiliza-se a semeadura de pastagens de inverno, uma vez que nesta estação, a capacidade da pastagem natural é reduzida. Portanto, o cultivo de pastagens de inverno serve para melhorar a capacidade produtiva da pastagem natural na estação em que esta perde parte de sua produtividade. Carvalho cita a aveia, o azevém, o cornichão e os trevos como exemplos de pastagens hibernais utilizados pelos produtores. ${ }^{43}$

Com a utilização dessas medidas, a produtividade pecuária pode ser aumentada drasticamente, de forma gradual dependendo da medida e dos níveis adotados. Conforme observado acima, importante destacar que muitas vezes o aumento da produtividade pode ser feito quase a custo zero, como é o caso do ajuste da carga animal, que não trará custos ao produtor.

Com base em um estudo desenvolvido pela Universidade Federal do Rio Grande do Sul, Aino V. A. Jacques e Carlos Nabinger apresentam os níveis de aumento de produção com a adoção das medidas supra citadas.

Com práticas tradicionais, a média de produtividade do Estado, medida em ganho de peso vivo/hectare/ano, fica em torno de $60 \mathrm{Kg}$. Considerando sistemas de recria e terminação de bovinos, comente com ajuste correto da carga animal (custo quase zero) são atingidos $230 \mathrm{Kg}$; com ajuste da carga mais correção de

\footnotetext{
39 Idem. p. 34.

40 Idem.

41 Idem. p. 55.

42 CARVAlHO, P.C.F. et al. Produção Animal no Bioma Campos Sulinos. Brazilian Journal of Animal Science, João Pessoa, v. 35, n. Supl. Esp., p. 156-202, 2006. s. p.

43 Idem.
}

REDESG / Revista Direitos Emergentes na Sociedade Global - www.ufsm.br/redesg v. 1, n. 2, jul.dez/2012

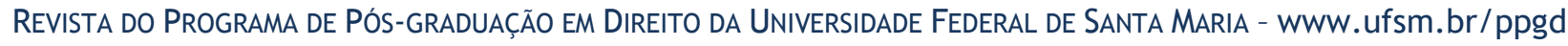


solo de base chega a $350 \mathrm{Kg}$; com a tecnologia anterior mais nitrogênio aumenta para $730 \mathrm{Kg}$, e com esta última prática mais a introdução de espécies forrageiras de estação fria ultrapassa $1000 \mathrm{Kg}$ de peso vivo/hectare/ano. ${ }^{44}$

De acordo com os dados apresentados pelos autores supra citados, verifica-se que a vegetação nativa do Bioma Pampa possui grande potencial de produtividade pecuária, uma vez que ao ser manejada corretamente pode chegar a um aumento produtivo de mais de dez vezes maior do que em pastagens nativas naturais, ou seja, onde não se adotaram medidas de otimização da produção. Ainda, destaca-se que com um custo muito baixo, quase a custo zero conforme os autores, a produtividade da pastagem natural pode aumentar quase quatro vezes, no caso do ajuste da carga animal.

Conforme referido alhures, a vegetação nativa é a base da alimentação dos animais criados no pampa, representando $69 \%$ da pastagem nas áreas onde se desenvolve a pecuária. Assim, a instituição da Reserva Legal em áreas onde a pecuária é desenvolvida com base na pastagem nativa não encontraria qualquer tipo de restrição, considerando que não há supressão da vegetação nativa, pelo contrário, existem possibilidades de melhoramento, o que significa preservação daquela vegetação, caracterizando o objetivo principal do instituto analisado, qual seja, manutenção da vegetação natural de cada região.

No que tange ao melhoramento referido supra, tratam-se das formas de aumento de produtividade das pastagens naturais analisadas anteriormente. Qualquer uma das formas existentes de melhoria dos campos nativos pode ser feita dentro das áreas de Reserva Legal, inclusive o cultivo de pastagens de estação fria, uma vez que estas forrageiras não substituirão a pastagem nativa. Pelo contrário, elas são cultivadas no inverno para que a produtividade não caia na estação do ano em que as pastagens naturais têm seu potencial reduzido. Trata-se de uma complementação da pastagem nativa durante o inverno, sendo que sempre existirá o campo natural. Portanto, desde que permaneça o campo nativo, há a possibilidade de desenvolvimento da atividade pecuária em áreas de Reserva Legal.

Nas demais propriedades rurais pecuaristas, que desenvolvem esta atividade com base em pastagens perenes, anuais de verão e anuais de inverno, a instituição da Reserva Legal também não traria prejuízos para a produção, uma vez que na área reservada a atividade pode ser desenvolvida normalmente, porém com a utilização de pastagens nativas como alimentação

\footnotetext{
${ }^{44}$ SIMPÓSIO DE FORRAGEIRAS E PRODUÇãO ANIMAL, 1.,2006, Porto Alegre. Anais. Biodiversidade dos Campos Sulinos. Porto Alegre: ULBRA, 2006. p. 9.

REDESG / Revista Direitos Emergentes na Sociedade Global - www.ufsm.br/redesg v. 1, n. 2, jul.dez/2012 Revista do Programa de Pós-graduação em DiReITO da Universidade Federal de SANTA MARIA - www.ufsm.br/ppgd
} 
para o gado, que como visto anteriormente, pode apresentar alta produtividade.

Nesta senda, de acordo com o analisado acerca da pecuária e das possibilidades de obtenção de bons resultados com a utilização da vegetação nativa do Bioma Pampa, verifica-se que a criação de gado é uma das formas de uso devido da área em que se instituiu a Reserva Legal, desde que tal área seja de campos, que não se suprima a vegetação nativa, sejam as gramíneas ou as poucas árvores encontradas, para a introdução de vegetação alienígena, e que sigam as demais regras previstas no Código Florestal, como a não alteração da finalidade ou modificação da área, por exemplo.

\section{CONCLUSÃO}

Diante da obrigatoriedade de instituição da Reserva Legal nas propriedades rurais, buscou-se analisar de que forma a pecuária desenvolveu-se no Rio Grande do Sul, mais especificamente no pampa, possibilitando, assim, observar se é uma atividade degradante ou preservadora do meio ambiente e em que condições pode auxiliar na proteção do Bioma Pampa.

$\mathrm{Na}$ primeira parte do trabalho, analisou-se o instituto da Reserva Legal, previsto no Código Florestal, que tem por finalidade a preservação da vegetação nativa de cada região, caracterizando-se pela reserva de uma área dentro de imóveis rurais onde a vegetação natural não pode ser suprimida e uma vez instituída não pode ter sua finalidade alterada. Na segunda parte buscou-se conceituar bioma e analisar os biomas existentes no Brasil, visando observar as características de cada um. Em seguida, verificou-se de forma mais aprofundada o Bioma Pampa, onde se procurou analisar as atividades rurais desenvolvidas, bem como as formas de degradação do bioma e de sua biodiversidade. Por fim, verificaram-se as formas como a pecuária é desenvolvida no pampa, de acordo com a base alimentar dos animais, buscando-se fazer um paralelo com a Reserva Legal, concluindo-se que a pecuária baseada em pastagens nativas, mesmo que melhorada pelo uso de tecnologias ou com a introdução de pastagens de estação fria, é uma das atividades que podem ser desenvolvidas dentro da Reserva Legal, por cumprir com as determinações e objetivos deste instituto.

Conforme se verificou no decorrer da pesquisa, a atividade pecuária desenvolvida no pampa, desde que tenha como fonte de alimentação a pastagem natural, é um dos elementos de preservação da biodiversidade encontrada nesta região. Importante ressaltar que a preservação 
no Bioma através da pecuária se dá se a base alimentar do gado for a vegetação nativa, que serve também como alimento de animais silvestres, mantendo o solo que a sustenta, etc., conforme já referido.

Cumpre destacar, ainda, que a Reserva Legal é um instituto que limita o uso indiscriminado da propriedade privada rural, na medida em que proíbe qualquer atividade que venha a suprimir a vegetação natural das diversas regiões do país, com o intuito de preservar a flora. Assim, por ser uma limitação ao uso da propriedade, o proprietário ou possuidor tem a obrigação legal de manter a vegetação nativa da área de Reserva Legal. Contudo, no caso do Bioma Pampa, não existe empecilho para a exploração da pecuária baseada nas pastagens nativas dentro das Reservas Legais, uma vez que mesmo havendo o melhoramento destas pastagens, não há a supressão da vegetação.

Constatou-se ao longo do estudo que ainda faltam esclarecimentos aos pecuaristas sobre os potenciais da pastagem nativa no Bioma Pampa, bem como sobre o próprio instituto da Reserva Legal. Muitos ainda têm medo de instituí-la por não terem conhecimento de que pode haver produtividade mesmo na área reservada, desde que não haja a supressão da vegetação nativa.

Enquanto as pesquisas sobre os campos nativos do Bioma Pampa permanecerem apenas nas universidades, sem chegar aos produtores, muito se perderá em termos de produção e em termos ambientais, uma vez que quanto mais produtiva se tornar a pastagem natural maior será o interesse do proprietário em mantê-la, preservando com isso não só aquela vegetação, mas todos os outros elementos que dela dependem, como os animais que se alimentam, o solo que a sustenta, dentre outros. Da mesma forma, enquanto não houverem maiores esclarecimentos acerca da Reserva Legal, um instituto obrigatório para todas as propriedades rurais, os produtores não terão consciência de que este instrumento além de preservar o meio ambiente pode também ser produtivo, caracterizando a sustentabilidade tão falada atualmente, onde se produzirá preservando a natureza.

\section{REFERÊNCIAS}

BRASIL. Decreto $\mathrm{n}^{\circ} 23.793,23$ de janeiro de 1934. Aprova o Código Florestal que com este baixa. Diário Oficial da República Federativa do Brasil, Brasília, DF, 21 mar. 1935. Disponível em: < 
http://www.planalto.gov.br/ccivil_03/decreto/1930-1949/d23793.htm> Acesso em: 28 nov. 2012.

Lei 4.771, 15 de setembro de 1965. Institui o novo Código Florestal. Diário Oficial da República Federativa do Brasil, Brasília, DF, 16 set. 1965. Disponível em <http://www.planalto.gov.br/ccivil_03/Leis/L4771.htm> Acesso em: 28 mai. 2010.

. Lei $\mathrm{n}^{\circ}$ 12.651, 25 de maio de 2012. Dispõe sobre a proteção da vegetação nativa. Diário Oficial da República Federativa do Brasil, Brasília, DF, 28 mai. 2012. Disponível em < http://www.planalto.gov.br/ccivil_03/_Ato2011-2014/2012/Lei/L12651.htm> Acesso em: 27 nov. 2012.

- Instituto Brasileiro de Geografia e Estatística (IBGE). Disponível em: <http://www.ibge.gov.br/home/presidencia/noticias/noticia_visualiza.php?id_noticia=169> Acesso em: 29 mai. 2010.

CARVALHO, P.C.F. et al. Produção Animal no Bioma Campos Sulinos. Brazilian Journal of Animal Science, João Pessoa, v. 35, n. Supl. Esp., p. 156-202, 2006. s. p.

COUTINHO, Leopoldo Magno. O conceito de bioma. Acta Bot. Bras., São Paulo, v. 20, n. 1, mar. 2006 . Disponível em <http://www.scielo.br/scielo.php?script=sci_arttext\&pid=S0102$33062006000100002 \&$ lng=pt\&nrm=iso>. Acesso em 27 de maio de 2010.

DUTRA, Ozório Vieira. Reserva legal: direito ambiental. São Borja: Conceito, 2009. p.

GOMES, Elissandra et. al. 0 impacto da crise econômica americana no bioma pampa. Disponível em: <http://www.eumed.net/cursecon/ecolat/br/08/gpfrmp.htm> Acesso em: 02 jun. 2010.

GRANZIERA, Maria Luiza Machado. Direito ambiental. São Paulo: Atlas, 2009. 
ISSN 2316-3054

MALVEZZI, Roberto. Os biomas brasileiros. Disponível em: <http://www.coepbrasil.org.br/portal/Publico/apresentarArquivo.aspx?ID=2097 > Acesso em: 31 mai. 2010.

MILARÉ, Edis. Direito do ambiente: doutrina, jurisprudência, glossário. São Paulo: Revista dos Tribunais, 2007.

PEDREIRA, Carlos Guilherme Silveira. Avanços metodológicos na avaliação de pastagens. Piracicaba: USP.

ROCHA, Leonel Severo. Epistemologia Jurídica e Democracia. São Leopoldo: UNISINOS, 1998.

SEMINÁRIO SULAMERICANO DO BIOMA PAMPA, 1., 2006, Alegrete. Bioma Pampa. Alegrete: IBAMA, 2006.

SIMPÓSIO DE FORRAGEIRAS E PRODUÇÃO ANIMAL, 1.,2006, Porto Alegre. Anais. Biodiversidade dos Campos Sulinos. Porto Alegre: ULBRA, 2006.

SIRVINSKAS, Luís Paulo. Manual de direito ambiental. São Paulo: Saraiva, 2009.

Recebido em: 28.11.2012

Revisado em: 26.02.2013

Aprovado em: 07.03.2013 